\title{
Modelagem do crescimento e do desenvolvimento de frangos de corte: validação
}

\author{
Modeling of the growth and development of broilers: validation
}

\author{
Gilberto D’Avila Vargas ${ }^{1}$ Nelson Laurino Dionello² Paulo Antônio Rabenschlag de Brum ${ }^{3}$ \\ Fernando Rutz ${ }^{2}$ Flávio Bello Fialho ${ }^{4}$
}

\section{- REVISÃO BIBLIOGRÁFICA -}

\section{RESUMO}

Foi desenvolvido um modelo com o objetivo de simular o metabolismo basal, a deposição de proteína na carcaça e nas penas e a deposição de gordura na carcaça. O modelo assume a existência de um "pool” de nutrientes disponíveis no corpo animal, sendo a simulação do metabolismo animal baseada no fluxo de entrada e saída de nutrientes desse "pool". Os nutrientes vêm da ingestão de alimentos ou do catabolismo tecidual, são removidos do "pool" com os destinos de mantença, deposição de proteína na carcaça, deposição de gordura na carcaça e deposição de proteína nas penas. O processo de simulação é dinâmico, com as exigências de mantença contabilizadas ao mesmo tempo que as deposições de tecidos. Três conjuntos de dados foram utilizados para o processo de calibração, de análise de sensibilidade dos parâmetros e de validação do modelo. $O$ modelo é eficaz para simular a deposição de proteína e de gordura na carcaça, bem como a deposição de proteína nas penas. No entanto, há a necessidade de um ajuste nos parâmetros envolvidos nas deposições de acordo com o genótipo que se pretende simular, principalmente para a taxa de maturação da proteína na carcaça $\left(B_{p}\right)$, para a taxa de maturação da proteína nas penas $\left(B_{F}\right)$, para o peso maduro da proteína na carcaça $\left(W_{p}\right)$ e para o peso maduro da proteína nas penas $\left(\mathrm{Wm}_{\mathrm{F}}\right)$. O modelo mostrou-se especialmente sensível a estes parâmetros na análise de sensibilidade, salientando-se a importância de serem corretamente determinados. As deposições de proteína na carcaça e nas penas apresentaram menores coeficientes de correlação $\left(r^{2}\right)$ entre os valores observados e simulados em função da grande variação entre genótipos, o que reforça a necessidade de se determinar corretamente os parâmetros que caracterizam cada genótipo.
Palavras-chave: tecido muscular, tecido adiposo, mantença, catabolismo, penas, metabolismo, deposição de tecido.

\section{ABSTRACT}

A model was developed in order to simulate the basal metabolism, deposition of protein in carcass and feathers and carcass fat deposition. The model assumes the existence of a pool of readily available nutrients in the animal body, being the simulation of animal metabolism based on the in and out flow of nutrients of this pool. Nutrients come from feed intake or tissue catabolism, and may be used for maintenance, feather and carcass protein deposition and carcass fat deposition. The simulation process is dynamic, with maintenance and tissue turnover occurring simultaneously. Three data sets were used for calibration, sensibility analysis and validation of model. The model is able to simulate deposition of protein and fat in the carcass and protein in the feathers. However, adjustments are required to match different genotypes, mainly for the rate of maturing of the protein in the carcass $(B P)$, rate of maturing of the protein in the feathers $(B F)$, for the mature weight of the protein in the carcass $(\mathrm{WmP})$ and the mature weight of the protein in the feathers (WmF). The model was especially shown sensitive to these parameters in the sensibility analysis, being highlighted the importance of being correctly determined. The protein deposition in the carcass and in the feathers they presented smaller correlation coefficients $\left(r^{2}\right)$ among the observed values and simulated in function of the great variation among genotypes, what reinforces the need to determine the parameters that characterize each genotype correctly.

Key words: lean tissue, fat tissue, maintenance, catabolism, feathers, metabolism, tissue deposition.

\footnotetext{
${ }^{1}$ Departamento de Veterinária Preventiva, Universidade Federal de Pelotas (UFPel), 96010-900, Pelotas, RS, Brasil. E-mail: gilbave@ufpel.tche.br. Autor para correspondência.

${ }^{2}$ Departamento de Zootecnia, Faculdade de Agronomia Eliseu Maciel, UFPel. Pelotas, RS, Brasil.

${ }^{3}$ Embrapa Suínos e Aves, Concórdia, SC, Brasil.

${ }^{4}$ Embrapa Uva e Vinho, Bento Gonçalves, RS, Brasil..
} 


\section{INTRODUÇÃO}

Modelagem é a abstração e simplificação da realidade capaz de integrar as principais interações e o principal comportamento do sistema estudado, apta a ser manipulada com o objetivo de prever as conseqüências da modificação de um ou de vários parâmetros sobre o comportamento do sistema (SPEDDING, 1988). A modelagem é, sobretudo, uma tentativa de integração de diferentes fenômenos, sendo limitada pelos recursos humanos e pelos materiais disponíveis e/ou utilizados na sua construção (LOVATTO \& SAUVANT, 2001). A modelagem computacional é uma alternativa para ajudar na tomada de decisões e na definição de produtos melhores e mais econômicos, tanto na indústria como na pesquisa (SPEDDING 1988; BLACK, 1995).

O desenvolvimento de modelos que simulam processos fisiológicos, como o metabolismo basal e a deposição de tecidos, tornam-se necessários não só para o estudo e a compreensão destes processos nas aves, mas servem também como uma ferramenta para o aprofundamento nos processos envolvidos, assim como para a identificação de lacunas no conhecimento (MCNAMARA et al., 2000). O objetivo deste trabalho é o de apresentar a calibração e a validação de um modelo do crescimento e do desenvolvimento de frangos de corte descrito e implementado por VARGAS et al. (2005).

Pré-calibração

A calibração tem por finalidade promover ajustes em alguns parâmetros do modelo para que os resultados simulados tenham um comportamento semelhante aos resultados experimentais. Para a précalibração e a calibração do modelo, foram utilizados os dados experimentais da composição das dietas, do consumo de ração, do ganho de peso e da composição de carcaça (peso da proteína e peso da gordura) de KOLLING(2001).

Antes da calibração do modelo, foi realizada uma etapa denominada de pré-calibração, no qual foram feitos testes para a determinação dos valores das constantes reguladoras da deposição de proteína limitada pelo nitrogênio $\left(k_{\mathrm{N}}\right)$, da deposição de gordura $\left(\mathrm{k}_{\mathrm{G}}\right)$ e da deposição de proteína limitada pela energia $\left(\mathrm{k}_{\mathrm{E}}\right)$. Como essas constantes não constam na literatura, foi necessário determiná-las para que o modelo pudesse ser estudado. O critério utilizado para as determinações foi o efeito da variação do valor destas constantes no peso corporal, na proteína e na gordura na carcaça aos 49 dias de idade das aves, buscando, por meio das simulações, atingir a maximização do peso corporal, mas, ao mesmo tempo, também um equilíbrio entre a deposição de proteína e gordura na carcaça. Isso porque aumentos exagerados para $\mathrm{k}_{\mathrm{N}}$ ou $\mathrm{k}_{\mathrm{G}}$ acarretam num desequilíbrio na deposição de proteína gordura na carcaça, o que difere de um organismo em crescimento normal. A dieta utilizada para essas determinações continha um alto teor de proteína, buscando, dessa forma, que o nitrogênio não fosse limitante. Primeiramente, fixou-se $\mathrm{k}_{\mathrm{N}}$ e $\mathrm{k}_{\mathrm{E}}$ em 1 e determinou-se o menor valor de $\mathrm{k}_{\mathrm{G}}$ suficiente para maximizar o peso corporal, sendo o valor escolhido o de 0 ,4. Com o valor de $\mathrm{k}_{\mathrm{G}}$ fixo em 0,4 e o de $\mathrm{k}_{\mathrm{E}}$ fixo em 1 , determinou-se o valor de $\mathrm{k}_{\mathrm{N}}$ igual a 4 como o menor valor suficiente para maximizar o ganho de peso. $\mathrm{O}$ teste foi repetido sucessivamente, alternando-se entre $\mathrm{k}_{\mathrm{G}}$ e $\mathrm{k}_{\mathrm{N}}$, até que se obtivessem os valores estáveis de $\mathrm{k}_{\mathrm{G}}=0,7$ e $\mathrm{k}_{\mathrm{N}}=6$. Após as determinações de $\mathrm{k}_{\mathrm{N}}$ e $\mathrm{k}_{\mathrm{G}}$, foram testados valores dentro de uma ampla faixa de variação de $k_{E}$ (0,001 a 10), tendo o modelo apresentado pouca sensibilidade a este parâmetro, optando-se pelo valor de $\mathrm{k}_{\mathrm{E}}$ igual a 1 .

\section{Análise de correlação}

A análise de sensibilidade do modelo tem por finalidade identificar os parâmetros mais sensíveis à variação em seus valores originais. Assim como na pré-calibração e na calibração, foram usados na análise de sensibilidade dos parâmetros os dados experimentais de KOLLING (2001). Os parâmetros do modelo foram submetidos ao teste de sensibilidade com uma dieta de alta energia e com uma dieta de alta proteína. Mediante alteração dos valores originais dos parâmetros, foi medida a taxa de variação no peso corporal $(W, g)$, no peso da gordura na carcaça $(G, g)$, no peso da proteína na carcaça $(\mathrm{P}, \mathrm{g})$ e no peso da proteína nas penas (F, g). Alguns parâmetros mostraram-se mais sensíveis às alterações, principalmente a taxa de maturação da proteína na carcaça $\left(\mathrm{B}_{\mathrm{p}}\right)$, a taxa de maturação da proteína nas penas $\left(B_{F}\right)$, o peso na maturidade da proteína na carcaça $\left(\mathrm{Wm}_{\mathrm{p}}\right)$ e o peso na maturidade da proteína nas penas $\left(\mathrm{Wm}_{\mathrm{F}}\right)$.

\section{Calibração}

Na etapa de calibração do modelo, o objetivo foi de melhorar a estimativa da deposição de proteína na carcaça e nas penas, sendo determinados novos valores de taxa de maturação da proteína na carcaça $\left(\mathrm{B}_{\mathrm{p}}\right)$, de peso na maturidade da proteína na carcaça $\left(\mathrm{Wm}_{\mathrm{p}}\right)$, de taxa de maturação da proteína nas penas $\left(B_{F}\right)$ e de peso na maturidade da proteína nas penas $\left(\mathrm{Wm}_{\mathrm{F}}\right)$. Essas determinações foram realizadas porque 
os valores utilizados para esses parâmetros na précalibração foram obtidos da literatura, a partir de genótipos de frango de corte que depositavam uma quantidade de proteína na carcaça e nas penas mais baixa que a dos genótipos atuais.

Como a constante reguladora de deposição de proteína limitada pelo nitrogênio $\left(\mathrm{k}_{\mathrm{N}}\right)$ influencia na deposição protéica, novos valores para esta constante foram determinados simultaneamente. Os valores de $B_{P}$ e $B_{F}$ foram corrigidos juntos, sendo multiplicados por um mesmo fator de correção. O mesmo foi feito para $\mathrm{W}_{\mathrm{mP}} \mathrm{e} \mathrm{W}_{\mathrm{mF}}$, que também foram corrigidos juntos. Para $B_{\mathrm{P}}$ e $\mathrm{B}_{\mathrm{F}}$, foi determinado um fator de correção de 1,24 vezes para machos e de 1,09 vezes para fêmeas; e para $W_{\mathrm{P}}$ e Wm , um fator de correção de 1,105 para machos e de 1,675 vezes para fêmeas, em comparação aos valores determinados por GOUS et al. (1999). O valor de $\mathrm{k}_{\mathrm{N}}$ para machos e para fêmeas foi determinado como sendo 2,4 e 3,4, respectivamente.

Duas dietas experimentais (KOLLING, 2001) foram utilizadas para calibrar o modelo. Uma delas apresentava alta relação calórico-protéica, sendo denominada de tratamento E (2977,9kcal/kg de energia metabolizável corrigida para nitrogênio (EMAn) e $18,87 \%$ de proteína bruta (PB) no período de 1-21 dias de idade, $E M A n=3.061,0 \mathrm{kcal} / \mathrm{kg}$ e $\mathrm{PB}=16,83 \%$, de 21 a 49 dias de idade). A segunda dieta utilizada apresentava baixa relação calórico-protéica e foi denominada de tratamento $\mathrm{P}(\mathrm{EMAn}=2956,2 \mathrm{kcal} / \mathrm{kg}$ e $\mathrm{PB}=22,94 \%$ de 1-21 dias de idade; $\mathrm{EMAn}=3048,4 \mathrm{kcal} / \mathrm{kg}$ e $\mathrm{PB}=21,72 \%$, de 21 a 49 dias de idade). Como critério para o ajuste dos parâmetros $\mathrm{B}_{\mathrm{P}}, \mathrm{B}_{\mathrm{F}}, \mathrm{Wm}$, Wm $\mathrm{F}_{\mathrm{F}}$ e $\mathrm{K}_{\mathrm{N}}$, foi estabelecido que o peso da proteína na ${ }^{\mathrm{P}}$ carcaça aos 49 dias para o tratamento E e o peso da proteína na carcaça aos 21 e 49 dias de idade para o tratamento $P$ deveriam coincidir com os valores observados por KOLLING (2001). Validação

A validação do modelo foi realizada por meio de comparações com 2 conjuntos de dados experimentais: NRC (1994) e LONGO (2000), dos quais foram utilizados os dados de composição das rações, de consumo de ração e de composição corporal de machos e fêmeas.

Os dados de peso corporal indicados pelo NRC (1994) para frangos de corte de 0 a 49 dias de idade, os dados da simulação do modelo pré-calibrado (Simulado 1) e os dados da simulação do modelo calibrado (Simulado 2) são mostrados nas figuras 1 e 2 para machos e fêmeas, respectivamente.

Nessas figuras, é verificado que a curva de crescimento dos frangos, de acordo com o NRC (1994), é uma típica curva sigmoidal, ou seja, com a primeira parte de formato côncavo, onde a taxa de crescimento é acelerada, sendo que, com o avanço da idade, a taxa de crescimento passa de acelerada para desacelerada, com ganhos de peso proporcionalmente menores. $\mathrm{O}$ ponto de mudança do padrão de aceleração, chamado ponto de inflexão, é o ponto da curva em que esta passa de côncava para convexa. Tanto no primeiro processo de simulação (Simulado 1) como no segundo (Simulado 2), foi observado um comportamento semelhante aos dados experimentais (observado), porém a curva de crescimento produzida pelo Simulado 2 esteve acima dos dados observados a partir de 21 dias de idade das aves. Possivelmente esta estimativa maior para o peso corporal possa ser explicada pelo

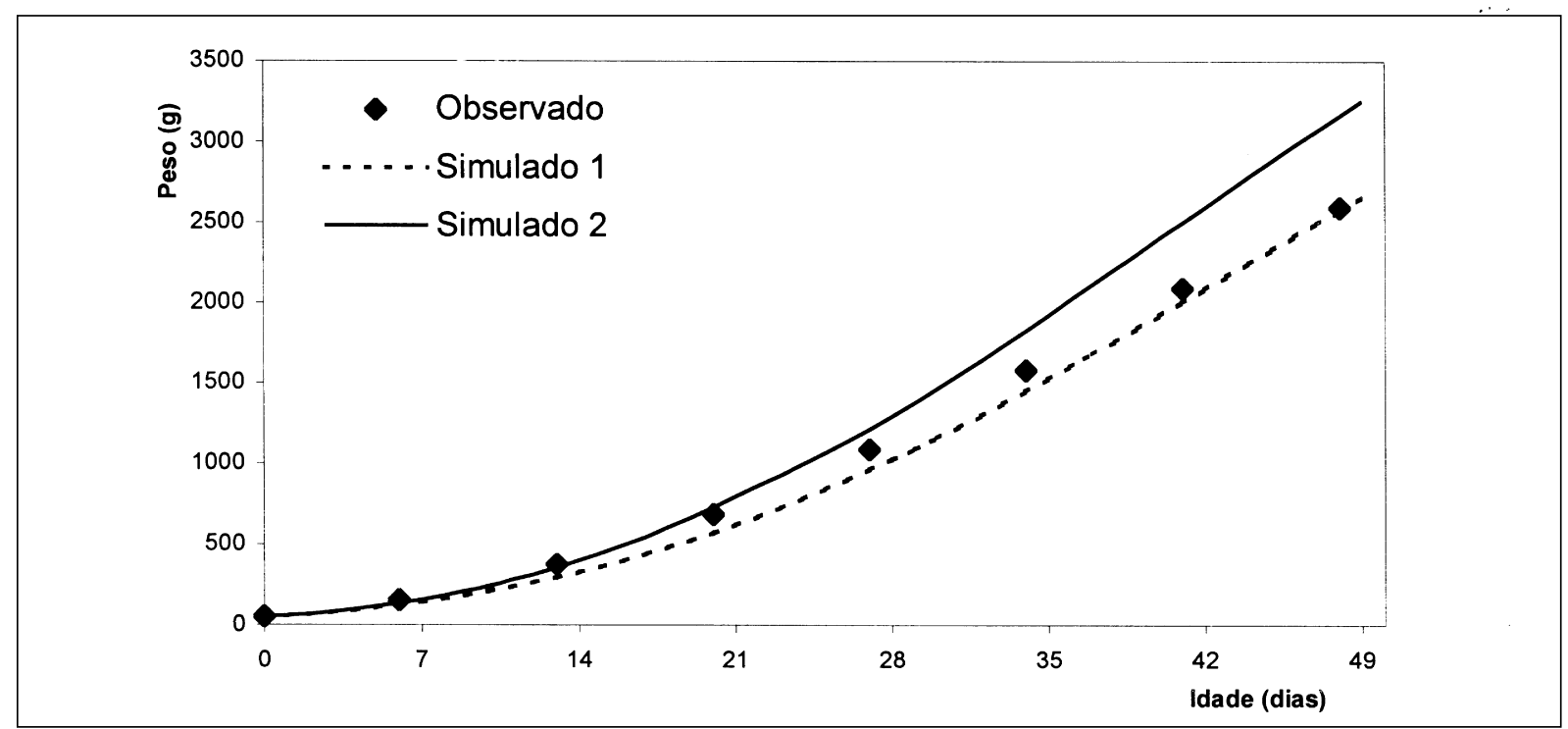

Figura 1 - Peso corporal (g) de frangos de corte machos estimado pelo NRC (1994) e simulado pelos modelos pré-calibrado (simulado 1) e calibrado (simulado 2 ).

Ciência Rural, v.36, n.5, set-out, 2006. 


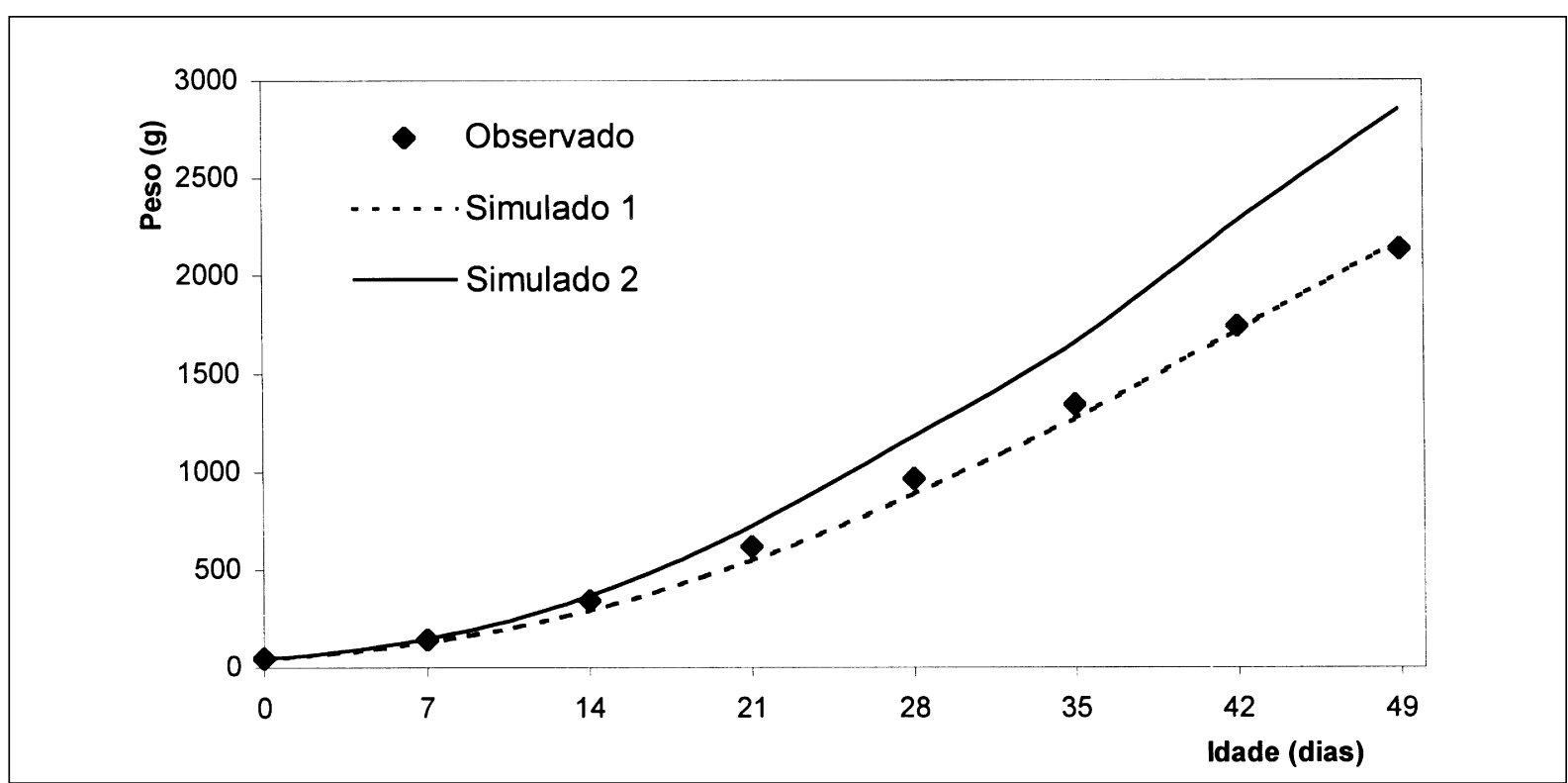

Figura 2 - Peso corporal (g) de frangos de corte fêmeas estimado pelo NRC (1994) e simulado pelos modelos pré-calibrado (simulado 1) e calibrado (simulado 2).

fato de que as aves usadas para obter-se os valores propostos pelo NRC (1994) eram aves cujo genótipo se aproximava mais do genótipo das aves de GOUS (1999), cujo experimento foi realizado em 1989. Essas aves caracterizavam-se por uma menor deposição de proteína, o que irá resultar num menor ganho de peso, principalmente por efeito da água, que deixa de ser depositada junto com a proteína, ou seja, uma menor deposição de água leva a um menor peso corporal.

Na figura 3, é feita a comparação com o conjunto de dados experimentais de LONGO (2000), onde são mostrados o peso da proteína na carcaça (g), o peso da gordura na carcaça (g), o peso da proteína nas penas (g) e o peso corporal (g) para frangos de corte machos de 0 a 49 dias de idade para as simulações do modelo pré-calibrado (Simulado 1) e calibrado (Simulado 2). A deposição de proteína na carcaça seguiu um comportamento considerado normal para as duas simulações, ou seja, a deposição diária de proteína corporal aumentou na fase côncava da curva de crescimento e alcançou o máximo (ou platô) na fase linear ou de inflexão. Porém, após 21 dias de idade das aves, o Simulado 2 superestimou o peso da proteína na carcaça até 49 dias de idade. Isto pode ser explicado porque a calibração do modelo foi feita utilizando os dados de aves que tiveram uma taxa maior de deposição de proteína na carcaça do que as aves utilizadas por LONGO (2000). O Simulado 1 apresentou uma deposição de proteína mais próxima, porém menor que a dos dados experimentais.
Com relação ao peso da gordura na carcaça, o Simulado 2 foi o que mais se aproximou dos dados experimentais. Enquanto isso, o Simulado 1 determinou uma deposição de gordura muito maior, possivelmente porque simulou uma baixa deposição de proteína e, com isto, tanto a proteína que não foi depositada quanto a energia que deveria ser usada para esta deposição foram utilizadas para a síntese de gordura na carcaça.

O peso da proteína nas penas foi mais bem estimado pelo Simulado 2 devido ao ajuste na deposição de proteína feito na calibração do modelo ter sido adequado para a deposição de proteína nas penas. Isso não aconteceu com o Simulado 1 , que não sofreu ajuste para a deposição de proteína.

Com o peso da proteína na carcaça sendo superestimado pelo Simulado 2, o peso corporal também foi, pois a proteína na carcaça tem uma maior influência no peso corporal que a gordura. Como já mencionado, o tecido protéico apresenta uma grande quantidade de água, contribuindo assim para o aumento do peso corporal.

Na figura 4, são mostrados os pesos da proteína na carcaça, da gordura na carcaça, do peso da proteína nas penas e do peso corporal para fêmeas de 0 a 49 dias de idade para os dados experimentais de LONGO (2000), Simulado 1 e Simulado 2. Para as fêmeas, as simulações tiveram o mesmo comportamento que para os machos tanto no Simulado 1 como no Simulado 2, em relação aos dados experimentais. 


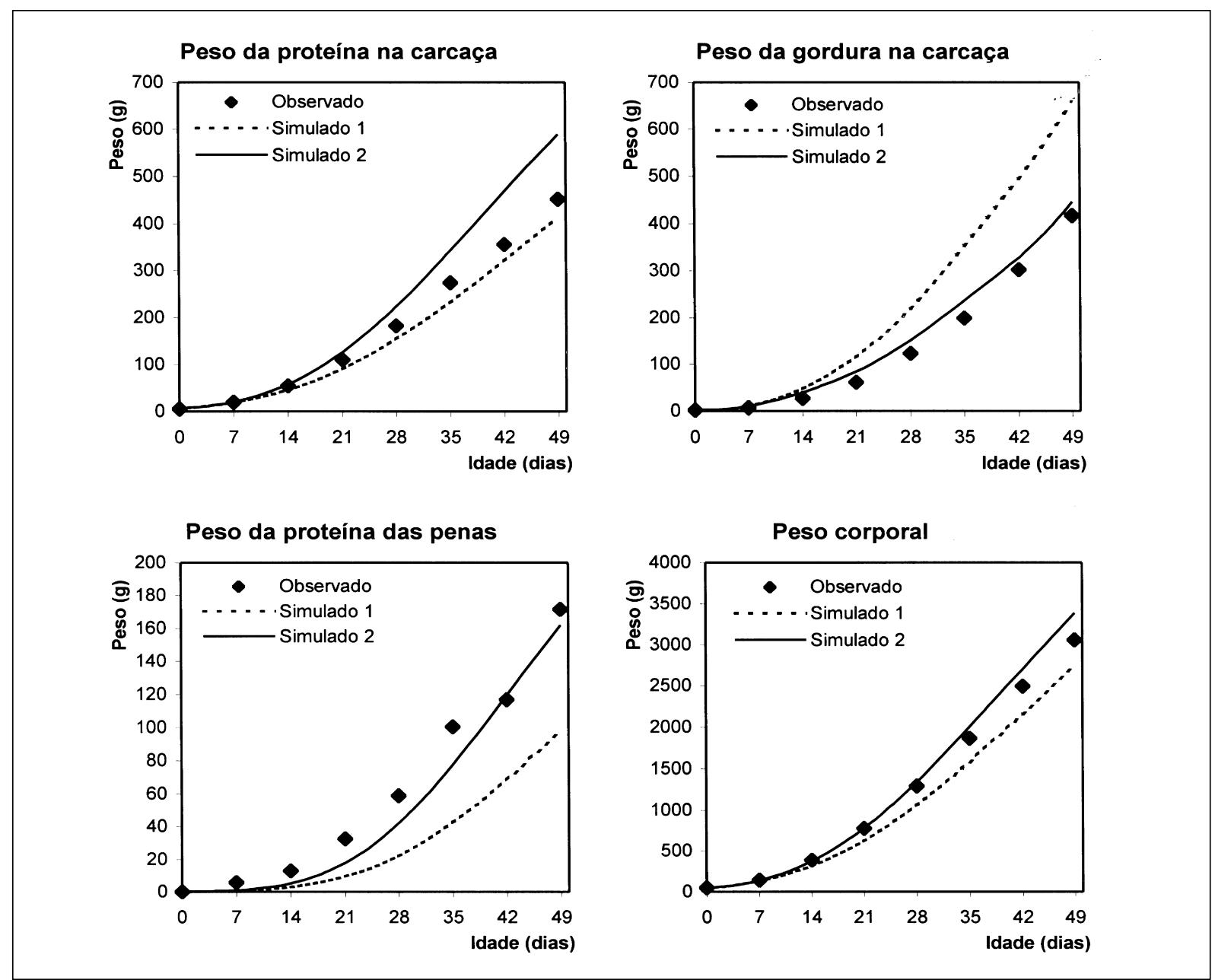

Figura 3 - Pesos (g) da proteína e da gordura na carcaça, da proteína nas penas e peso corporal de frangos de corte machos de 0 a 49 dias de idade observados por LONGO (2000) e simulados pelos modelos pré-calibrado (simulado 1) e calibrado (simulado 2).

Análise de correlação

Foi feita a determinação dos coeficientes de correlação $\left(\mathrm{r}^{2}\right)$ entre os valores observados e os valores simulados pela Simulação 1 e pela Simulação 2 para peso corporal, gordura na carcaça, proteína na carcaça e proteína nas penas (Tabela 1). De uma maneira geral, os coeficientes de correlação foram elevados, com algumas considerações a serem feitas para proteína na carcaça e proteína nas penas, que apresentaram $\mathrm{r}^{2}$ mais baixos. Provavelmente as taxas de maturação para proteína na carcaça $\left(\mathrm{B}_{\mathrm{p}}\right)$, para proteína nas penas $\left(\mathrm{B}_{\mathrm{F}}\right)$, o peso na maturidade para proteína na carcaça (Wm ) e o peso na maturidade para proteína nas penas em gramas $\left(\mathrm{Wm}_{\mathrm{F}}\right)$ determinados na etapa de calibração do modelo não estejam de acordo com o genótipo comparado. Isso demonstra que é importante a determinação correta desses parâmetros para o genótipo que está sendo avaliado.

\section{CONCLUSÕES}

O modelo de simulação de crescimento e desenvolvimento de frango de corte desenvolvido é eficaz para simular a deposição de proteína e gordura na carcaça, bem como a deposição de proteína nas penas. No entanto, há necessidade de ajuste nos parâmetros envolvidos nas deposições de acordo com o genótipo que se pretende simular, principalmente naqueles relacionados com a deposição de proteína.

\section{AGRADECIMENTOS}

A Professora Nilva Sakomura e ao Pesquisador Flávio Alves Longo, da Universidade Estadual Paulista (Unesp), Jaboticabal, e ao Professor Alexandre de Mello Kessler, da Universidade Federal do Rio Grande do Sul (UFRGS), pelo fornecimento de dados experimentais utilizados no estudo do modelo. 


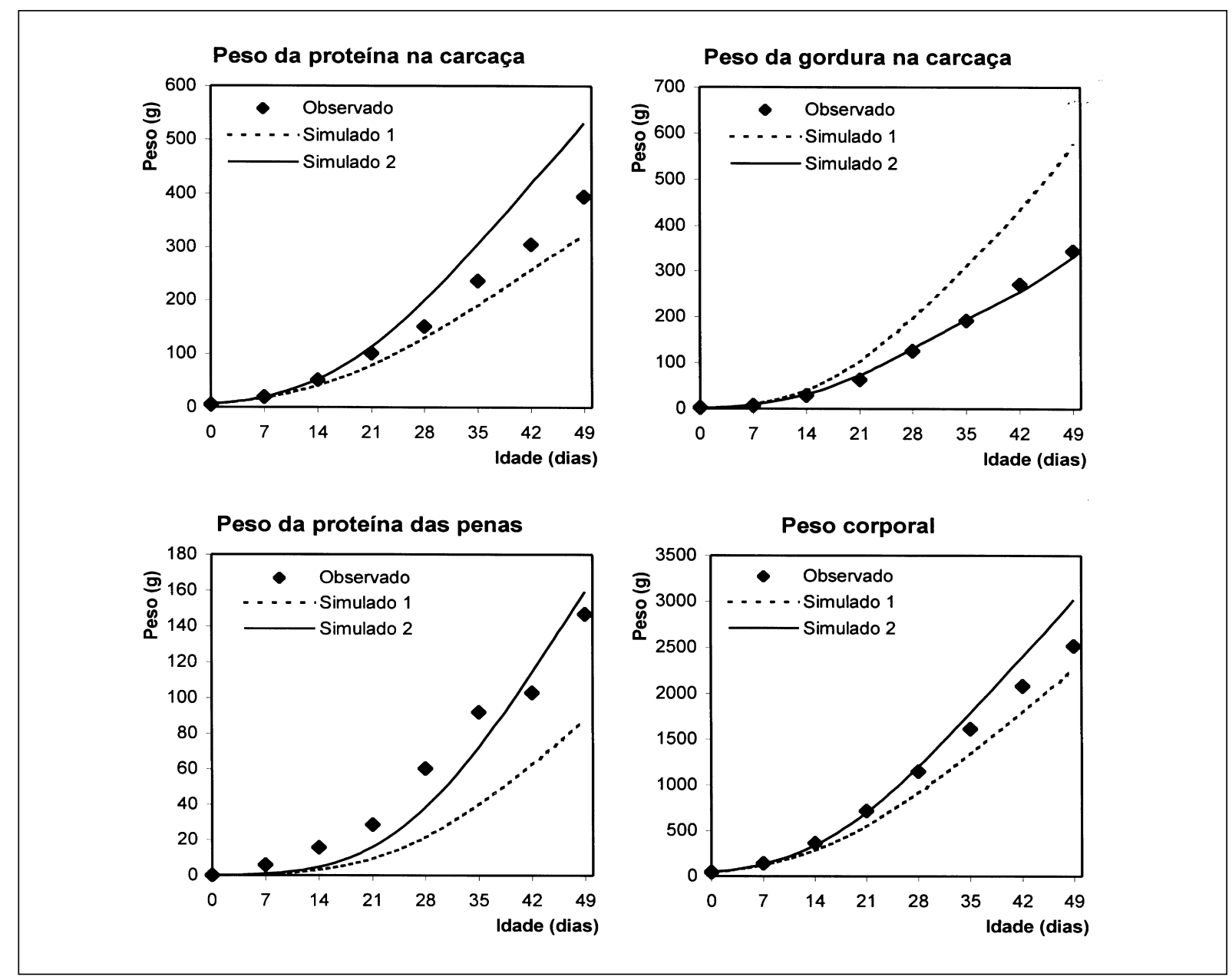

Figura 4 - Pesos (g) da proteína e da gordura na carcaça, proteína nas penas e peso corporal de frangos de corte fêmeas de 0 a 49 dias de idade observados por LONGO (2000) e simulados pelos modelos pré-calibrado (simulado 1) e calibrado (simulado 2).

\section{REFERÊNCIAS}

BLACK, J.L. The evolution of animal growth models. In: MOUGHAN P.J. et al. (Ed). Modelling growth in the pig. The Netherlands: Wageningen, 1995. p.3-9.

GOUS, R.M. Evaluation of the parameters needed to describe the overall growth, the chemical growth, and the growth of feathers and breast muscles of broilers. Poultry Science, v.78, p.812-821, 1999

KOLLING, A.V. Efeito da relação calórico:protéica da dieta sobre as curvas de crescimento corporal de frangos de corte de 1 a 49 dias de idade. 2001. 155f. Dissertação (Mestrado em zootecnia) - Faculdade de Agronomia, UFRGS.

LONGO, F.A. Estudo do metabolismo energético e do crescimento de frangos de corte. 2000. 76f. Dissertação (Mestrado em zootecnia) - Faculdade de Ciências Agrárias e Veterinárias, Unesp Jaboticabal, SP.
LOVATTO, P.A.; SAUVANT, D. Modelagem aplicada aos processos digestivos e metabólicos do suíno. Ciência Rural. v.31, n.4, p.663-670, 2001.

MCNAMARA, J.P. et al. Modeling nutrient utilization in farm animals. London (UK): CAB International, 2000. 22p.

NATIONAL RESEARCH COUNCIL. Nutrient Requirements of poultry. 9.ed. Washington DC: National Academy, 1994. 155p.

SPEDDING, C.R.W. General aspects of modelling and its application in livestock production. In: KORVER, S.; VAN ARENDONK, J.A.M. (Ed). Modelling of livestock production systems. Brussels (Belgium): Kluwer Academic, 1988. p.3-9.

VARGAS, G.D. et al. Modelo de simulação do crescimento e desenvolvimento de frangos de corte: descrição e implementação. Ciência Rural, v.35, n.2, p.440-445, 2005. 